\title{
Hidrazida del Acido Isonicotínico en el tratamiento de enfermas tuberculosas embarazadas
}

\author{
Por cl doctor Hernanio Amaya-León \\ Del Departamento de Ginecología y Obstetricia del Hospital Sanatorio de Santa Clara. \\ Profesor Agregado de Ginecología de la Facultad Nacional de Mericina.
}

Desck los trabajos de Rubin y col. ${ }^{1}$, Grunmberg y col. ${ }^{2}$, Sclikeff y Robitzek ${ }^{3}$ y otros autores americanos y curopeos, se ha visto que la quimioterapia con derivados del ácido Isonicotinico hal dado resultados muy sitisfactorios en la tuberculosis pulmonar $y$ ot ras localizaciones extrapulmonares.

Robitzch y col. ${ }^{4}$ en cste ano, comparando grupes de enfermos tratados con iproniazida y con isoniazida encuentran resultados muy similares entre los dos derivados, siendo un poco mejores los efectos sobre el estado general de los pacientes los obtenidos con la iproniazida, aungue también anotan su mayor toxi cidlad: consideran la desis de 8 miligramos por kilo de peso desis fraccionadas, la probable dosiliación optima de la isoniazida.

No nos fue posible oltener mayor información accrea de los resultados obtenides con la hidrazida del acide isonicotinico o isoniozida en enfermas emba razadas portadoras de kesionces tulerculesas pulmonares.

In este informe, presentames 16 cases de confermas cmbarazadas sufriendo de tulerculosis pulmonar tratadas en 1952 y 1953 (hasta mayo) con isoniazidas, solore un total de 24 cases atendides en dicho lapese en al 1 lospital Sanatorio Sinta Clara de Bogotí.

Todas las confermas estaban hospitalizadas y sometidas a los tratamientos usuales, médico-quirúrgicos. (V'anse cuadros en las paginas siguientes).

Es posible de la apreciación de estos casos deducir algunos datos de interés.

Las cofermas tratadias con isoniazida mejoraron apreciablemente tanto en su cstado general como en lo concerniente a sus lesiones pulmonares; su embarazo y parto transcurricron en forma similar a las mujeres que presentaban sus lesiones detenidas a cran francancente inactivas. Dete tenerse en cuenta que algunas de esas enfermas cran casos portadores de lesiones muy avanzadas.

Los casos 2 y 4 , no sometidos a tratamiento por isoniazidas o antibióticos, evolucionaron en forma francamente desfavorable. El fraciso en el caso 3 fue atribuido exclusivamente a la aplicación de pneumoperitóneo, contraindicado en casos de embarazo. 
1. Nidrazid, 200 mgrs. diarios durante 1 mes.

2. Sin tratamiento: entrada al Hospital para parto.

3. Estreptomicina, 30 gramos.

4. Sin antibióticos o quimioterapia.

5. Nidrazid. 200 mgrs. diarios por 2 meses y medio.

6. Rimifón, 200 mgrs. diarios por un mes.

7. Rimifón, 200 mgrs. diarios por 3 meses y 10 días.

8. Rimifón, $200 \mathrm{mgrs}$. diarios por 5 meses.

9. Rimifón, $150 \mathrm{mgrs}$. diarios por 5 meses.
Caseoneumónica cavitaria der. avanzada.

Caseoneumónica cavitaria bilateral muy avanzada.

Caseoneumónica cavitaria der.; exudativa productiva izq. muy avanz.

Caseoneumónica cavita- ++ ria der. avanzada.

Exudativa productiva bilateral moderada.

Caseoneumónica cavitaria izquierda avanzada.

Caseoneumónica cavitaria der. avanzada.

Caseoneumónica cavitaria bilateral avanzada.

Caseoneumónica cavitaria izq.; productiva der. muy avanzada.
(一) desde la droga.

$++$

(一) desde la droga.

(-) desde 15 dias de droga.

(一) desde la droga; luego ++ continua.

(-) desde la droga.

(一) desde 3 meses de droga

$(+)$; antes

$++$

\section{Forceps.}

Feto vivo

y normal. 10 horas. neo) (?) macerado.
Inactiva en la actualidad.

Muerte al tercer día. muerto a las

Aborto de 5 meses $y$ medio (penumoperitó-

Prematuro: feto

Espontáneo.

Feto normal.

Espontáneo.

Feto normal.

Espontáneo.

Feto normal.

Cesárea por inercia uterina.

Feto normal.

Retiro voluntario en mal estado.

Contr.: mismo estado.

Neumonectomía

10 meses después.

Inactiva; embarazada de nuevo actualmen'c.

Lobectomía 11 meses después.

Retiro luego de 5 meses. de inactividad.

Inactiva 7 meses después.

Regular estado actual. Resección pulmonar rechazada por enferma. 
10. Rimifón, 200 mgrs. diarios por 3 meses.

11. Sin tratamiento por inactividad de lesiones.

12. Nidrazid, 200 mgrs. diarios por 5 meses.

13. Nidrazid, 200 mgrs. diarios por 5 meses.

14. Sin tratamiento por inactividad de lesiones.

15. Sin tratamiento por lesiones detenidas.

16. Rimifón, 200 mgrs. diarios por 4 meses y medio.

17. Rimifón. 200 mgrs. diarios por dos meses.

18. Rimifón, 200 mgrs. diarios por 5 meses.
Caseoneumónica cavitaria de predominio der. avanzada.

Inactiva 2 años y medio. (-)

Caseoneumónica cavitaria der. moderada.

Caseoneumónica cavitaria der.; exudativa ulcerada izq. avanzada.

Inactiva por año $y$ medio.

Lesiones detenidas hace (-) más de 1 año.

Exudativas productivas ulceradas bilaterales av. Laringitis TBC.

Caseoneumónica cavitaria bilateral avanzada.

Caseoneumónica cavitaria bilateral avanzada.
(-) desde la droga.

(一) desde 1 mes de droga.

(一) desde 1 mes de droga.

$(-)$

\section{-)}

(一) desde 1 mes de droga.

(一) desde 1 mes de droga; luego $t$.

(一) desde $2^{9}$ mes de droga.
Espontáneo. Feto muerto por asfixia.

Forceps.

Niño normal.

Espontáneo.

Feto normal.

Forceps.

Feto normal.

Forceps.

Feto normal.

Espontáneo.

Feto normal.

Espontáneo.

Feto normal.

Cesárea e

histerectomía.

Feto normal.

Espontáneo.

Feto normal.
Retiro voluntario, activa pero mejorando.

Continúa bien.

Inactiva: embarazada de nuevo actualmente.

Lesiones detenidas.

Inactiva.

Continuaan lesiones detenidas.

Lesiones detenidas hace 3 meses.

Continúa hospitalizada: mejorando.

Continúa hospitalizada: mejorando. 


\section{Tratamiento}

19. Rimifón, 200 mgrs. diarios por 4 meses.

20. Rimifón, 200 mgrs. diarios por 2 meses.

21. Sin tratamiento por lesiones detenidas.

22. Rimifón, 200 mgrs. diarios por 6 meses.

23. Sin tratamiento por lesiones detenidas.

24. Rimifón, 200 mgrs. diarios por 3 meses.

\section{Forma Clínica}

Caseoneumónica cavitaria der.: exudativa productiva izq. avanzada.

Caseoneumónica cavitaria bilateral avanzada.

Lesiones detenidas.

Caseoneumónica cavitaria iza. moderad. avanz.

Lesiones detenidas.

Caseoneumónica bilateral cavitaria avanzada.

\section{Baciloscopia}

(-) desde 1

mes de droga.

(一) desde la droga.

(一)

$(+)$

(一)

$(+)$

\section{Parto}

Forceps.

Feto normal.

Espontáneo.

Feto normal.

Espontáneo.

Feto normal.

Espontáneo.

Feto normal.

Prematuro; gemelar.

Espontáneo.

Feto normal.

\section{Evolución posterior}

Continúa hospitalizad mejorando.

Salida voluntaria: lesiones detenidas.

Continúan lesiones detenidas.

Se practicó lobectomia.

Continúan lesiones detenidas.

Ligera mejoria: en observación. 
In los 16 casos tratades con isoniazida, no hulo delunciones maternas.

1t partos ( $87 \%$ ), se cfectuaron normalmente por las vias naturales; una cesirea y otra terminada con histerectomia, tuvicron su indicacion en necesida des obstetricis.

Se obuerieron 15 nimos (93\%) sanos y nomales, indice mus satisfactorio.

In 13 coses ( $81 \%$ ) la bacilosopia se hise negativa al cabo de cierto tiom $p^{n}$ de almimintracion de la ismiazida. en 11 de cotos $(68 \%)$, esa negatividad

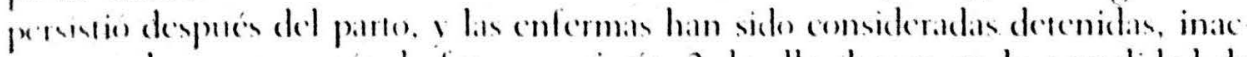
as.k, o al menos en via de franca mejoria: 2 de ellas hacen en la actualidad de nucow combarazo, y en muy buenas condiciones. D). 3 casos con baciloscopia presiciva a pesar de isoniazida, en uno de cllos al menes, se observo marcada mejoria en la intensidad de hallazgos bacilares; los otros no desmejoraron, siendo in todos, en cambio, notable la evolución satisfactoria de su estado general. Lstor 3 casos, y los dos de la seric anterior, fucron propuestos para tratamientos yuirúrgicos posteriores, encontrándose las enfermas en relativas buenas condiciones.

No se anotó en estos cuadros la curva de peso en las enfermas, pero se puede calcular que desde la iniciación de la administración de isoniazida en este grupo de enfermas, al mejorar al apetito y sucederse una favorable conversión diel estado general. el aumento de peso oseilo alrededor del doble de lo que po(li.) apreciarse en los mese's anteriores.

\section{SIIMARIO):}

1-Se presenta un grupo de 24 enfermas tuberculosas cmbarazadas.

2.-1) éstas, 16 fucron sometidas a trattamiento con hidrazida del ácido isoni cotínico.

3.- Los embarazos y partos transcurricron normalunente, sin defunciones ma ternas; 15 nimos (93\%) se encuentran sanos y normales.

4. - La mejoria del estato general y de las lesiones pulmonares fuc evidente en todas las enfermas; 11 cases (68\%) han continuado bien, siendo conside radas sus lesione's pulmonares inactivas o derenidas.

5.- La utilidad de la isoniazida en esta clase de enfermas es apreciable, y me jora sensiblemente el pronóstico tanto en la madre como en el niño.

\section{BIBLIOGRAFIA}

1.-Rubin S. H., Drekter L., Scheiner J., de Ritter E.-Determination of Blood Plasma Levels of Hydrazine Derivatives of Isonicotinic Acid. Dis. of Chest, XXI; 439, 1952.

2.-Grunberg E., Schnitzer R. J.--Studies of the Activity of Hydrazine Derivatives of Isonicotinic Acid in the Experimental Tuberculosis of Mice. Dis. of Chest, XXI; 389, 1952.

3.-Selikoff I. J., Robitzek E. H.-Tuberculosis Chemoterapy with Hydrazine Derivatives of Isonicotinic Acid. Dis. of Chest, XXI; 385, 1952.

4.--Robitzek E. H., Selikoff I. J., Mamlock E., Tendlau A.-Isoniazid and Its Isopropyl Derivative in the Therapy of Tuberculosis in Humans: Comparative Therapeutic and Toxicologic Properties. Dis. of Chest, XXII; 1, 1953. 